\title{
CDAN. ARTE CONTEMPORÁNEO EN EL HOSPITAL
}

\section{CDAN. Contemporary art at hospital}

\author{
Elena Del Diego \\ ARANTZA GRACIA \\ Dpto. de Educación del CDAN \\ didactica@cdan.es
}

Recibido: 15 de abril de 2011

Aprobado: 30 de mayo de 2011

\begin{abstract}
Resumen:
El CDAN busca acercar el arte contemporáneo a todos los colectivos, sin embargo hay un colectivo que difícilmente encuentra su hueco en el arte: aquellas personas que se encuentran hospitalizadas. Desde el CDAN se planteó el reto de acercar los contenidos del Centro a personas ingresadas en centros sanitarios. Este proyecto surge a partir de un trabajo de investigación junto con otros tres centros de arte, que nos había llevado a conocer el programa francés "Cultura à l'hôpital" que busca hacer del hospital un lugar más humano y abierto. Conocido este proyecto, surgió la posibilidad de trasladar algo similar a cada centro, con las diferentes realidades de cada uno. Para ello, se comenzó con un proceso de investigación teórica sobre las realidades de los hospitales. Y en la práctica, se trabajó con un taller de artista con el Centro de rehabilitación psico-social de Huesca y una fotógrafa zaragozana, Vicky Méndiz. El taller se realizó con personas con trastornos mentales y buscó dar a conocer el lenguaje y la técnica fotográfica y reflexionar sobre la percepción de la imagen corporal.
\end{abstract}

Palabras clave: CDAN, salud mental, hospital, taller de artista, Huesca.

Del Diego, E. Gracia, A. 2011: CDAN. Arte contemporáneo en el hospital. Arte, Individuo y Sociedad, Vol. 23, Núm. Especial, 213-227

\begin{abstract}
:
The aim of the CDAN is to bring the contemporary art over to all the groups; nevertheless there is a group that difficultly finds his hollow in the art: people who are hospitalized. Our work at CDAN takes the challenge of bringing the contents of the Centre over people admitted in a health centre. This project arises from a research project close to three other centres of art, which led us to know the French program Culture à l'hôpital that seeks to turn the hospital into a more human and opened place. Once this project was studied came up the possibility of transferring something similar to each centre and its different realities. Thus, we started a theoretical investigation process about the hospitals' realities; meantime, in practice, we designed a workshop with the Psico-social Rehabilitation Centre in Huesca and the local artist Vicky Méndiz. The participants were people with mental disorders. The aim of the workshop was teach the language and the technique of the photography and through this try to reflect about their own perception of the body image.
\end{abstract}

Key words: CDAN, mental health, hospital, artist's workshop, Huesca

Sumario: 1. Introducción. 2. La evaluación. 3. Conclusiones. Anexo I. Anexo II. Referencias. 


\section{Introducción}

El texto que aquí presentamos trata de mostrar algunas de las acciones que se han llevado a cabo desde el CDAN, Centro de Arte y Naturaleza de la Fundación Beulas, con el objeto de acercar el centro de arte a personas que por motivos de salud, no pueden desplazarse hasta él.

Uno de los objetivos fundamentales del CDAN es acercar el arte contemporáneo, y en concreto las colecciones del CDAN y las exposiciones que en el centro de arte se llevan a cabo, a la sociedad. Este objetivo se cumple ampliamente cuando las acciones van dirigidas a colectivos como escolares, educación de adultos, familias o público individual.

Sin embargo es obvio que quedan muchos sectores de la población, es decir, muchas personas en nuestra sociedad, que sienten o perciben que no tienen lugar en un museo, o mejor dicho que el museo no ha pensado un lugar (o un momento, o una acción) para ellos.

Dentro de este último grupo se encuentran las personas hospitalizadas, de forma permanente o transitoria, ya que a priori sería imposible que acudieran (físicamente) al museo o centro de arte, por lo que directamente ni se plantean la posibilidad de visitarlo.

Para las personas hospitalizadas el acceso a la cultura y al arte contemporáneo, considerado un derecho universal, es, en muchas ocasiones, una tarea imposible, debido a todos los condicionantes físicos (estar encamado, por ejemplo) y/o psíquicos (depresión, apatía...) que implica estar ingresado en un hospital.

Por todo ello, desde el CDAN nos planteamos una serie de acciones para cumplir con nuestro objetivo: hacer llegar los contenidos de nuestros fondos y salas de exposiciones a todas las personas.

Nos planteamos por lo tanto, acercar el arte contemporáneo a las personas hospitalizadas, usando nuevas estrategias y herramientas didácticas que pasan, sobre todo, por el desplazamiento de las educadoras y el diseño de un proyecto específico, teniendo en cuenta sus necesidades, capacidades y circunstancias personales.

Sin embargo, no son solo estos motivos los que nos llevan a emprender las acciones que más adelante desarrollaremos con personas hospitalizadas. Este proyecto surge a partir de un trabajo que venimos desarrollando en el CDAN desde 2008.

Ese año, gracias a una subvención de la Conselleria de Cultura de la Generalitat de Cataluña, comenzamos a trabajar un proyecto de investigación y formación en red junto al Centre d'Art la Panera, en Lérida, Es Baluard Museu d'Art Modern i Contemporani, en Palma de Mallorca, y CRAC Languedoc-Rousillon en Sète (Francia).

Este primer proyecto, denominado "Red de intercambio entre programas de educación especial de centros de arte contemporáneo de la Eurorregión Pirineos-Mediterráneo", tenía como objetivo realizar un recorrido formativo "a la carta" en el que las educadoras de dichos centros pudiéramos mejorar nuestra atención y en consecuencia la de nuestro museo, hacia las personas con discapacidad intelectual, demencia o con problemas de salud mental.

A lo largo de este primer proyecto de intercambio, se realizaron estancias en los cuatro centros participantes, donde se llevaron a cabo sesiones de trabajo con profe- 
sionales de diversos campos: la psiquiatría, la psicología, el trabajo social, el trabajo asistencial, la creación plástica, la música, la danza, etc.; así como visitas a diferentes centros tanto hospitalarios como asistenciales (residencias de personas con parálisis cerebral, unidades de psiquiatría...)

De este proyecto las profesionales participantes extrajimos un guión de buenas prácticas aplicable a los centros de arte contemporáneo, de cara a mejorar su atención a las personas con discapacidad intelectual, demencias o enfermedad mental.

Este proyecto concluyó con el II Seminario de arte contemporáneo y educación especial, que tuvo lugar en Lérida en junio de 2009, y con la publicación Arte contemporáneo y educación especial, a finales de 2010.

En el transcurso de este proyecto, durante nuestra estancia en Francia, pudimos conocer el programa "Cultura à l'hôpital" (Cultura en el hospital) fruto de un convenio firmado en 1999 entre el Ministerio de Cultura y Comunicación y el Secretariado de Estado de Salud y Acción social francés. Dicha iniciativa parte de la premisa:

La necesidad de hacer del hospital un lugar más humano, abierto a la ciudad, se reconoce como una prioridad del sector médico y hospitalario. Esta necesidad se traduce en nuevas políticas que mejoren la acogida y el acompañamiento de las personas hospitalizadas y de sus familias, y que aseguren al personal sanitario un marco profesional más agradable.

La cultura puede jugar un papel esencial en esta evolución. Sin intención de objetivos terapéuticos, esta participa en la mejora de la evolución de las personas y favorece la relación entre el hospital y su entorno. ${ }^{1}$

El Ministerio de Cultura y Comunicación destaca los siguientes puntos como los principales beneficios de la aplicación de este programa:

- Desde el sector sanitario, la entrada del arte en el hospital permite a la vez una acogida más humana y constituye una ocasión para abrirse a la ciudad y a sus recursos comunitarios.

- Desde el sector cultural, el hospital representa dentro de la ciudad un espacio privilegiado de encuentro entre los públicos; los artistas están interesados en participar, pues les permite un acercamiento a un público de otra naturaleza al que entra en contacto habitualmente en las salas de espectáculos o exposiciones; en cuanto a los equipamientos y las instituciones culturales, éstos ven la oportunidad de un trabajo fuera de sus instituciones, que favorece unas relaciones donde se construyen proyectos estables que permiten la participación de un segmento de población que no siempre es consumidor de productos culturales.

Después de haber visto el método y protocolo de funcionamiento de este programa, y con las experiencias que ya llevábamos acumuladas, nos resultó interesante la po-

1.Texto extraído del texto original del convenio firmado en 1999 entre los ministerios ya citados: Convention entre le Ministère de la Culture et de la Communication et le Secrétariat d'Etat à la Santè et à l'Action sociale. 
sibilidad de trasladar a nuestros museos y centros de arte un proyecto de similares objetivos, siempre teniendo en cuenta las diferentes realidades políticas, sociales y culturales entre España y Francia. De ahí surgió la idea de un nuevo proyecto de colaboración también financiado por la Generalitat de Catalunya denominado "Arte contemporáneo en el hospital".

Este proyecto pretendía establecer una red de investigación y de trabajo entre instituciones culturales y hospitalarias, con el objetivo de acercar la cultura y, especialmente, el arte contemporáneo, a todas aquellas personas que viven en un hospital, ya sea de forma temporal o permanente.

Los objetivos que nos planteamos al comenzar este nuevo proyecto fueron:

- Contribuir a mejorar la calidad de vida de los pacientes durante la estancia hospitalaria.

- Romper la rutina de la hospitalización en largas residencias.

- Ofrecer la posibilidad a los centros hospitalarios de tomar contacto con el ámbito artístico.

- Enseñar a ver y disfrutar del arte contemporáneo.

- Mostrar la posibilidad, a los profesionales del ámbito hospitalario, de utilizar el arte contemporáneo como una herramienta terapéutica (no planteamos el taller como una terapia, si no como un taller artístico que podríamos ofrecer a cualquier otro colectivo; si luego su uso resulta terapéutico, será solo gracias a la intervención del personal socio-sanitario).

En este punto establecimos unas pautas de trabajo. Se realizaría una sesión de formación con profesionales del área hospitalaria que realizasen un trabajo relacionado con el arte. Después de esta formación, cada centro realizaría uno o varios talleres (según las posibilidades de cada centro), siguiendo las pautas obtenidas del proyecto anterior. Para concluir, tendríamos un último encuentro donde pondríamos en común lo aprendido.

Nuestro único conocimiento respecto a las instituciones hospitalarias de Huesca se basaba en una visita realizada al Centro de rehabilitación psicosocial de Huesca. Dicha visita se realizó en 2009, en el marco del proyecto antes mencionado. Durante aproximadamente dos horas conocimos, de forma muy sumaria, la realidad de un centro hospitalario especializado en psiquiatría.

Del resto de áreas hospitalarias, desconocíamos totalmente su funcionamiento. Y de cualquiera de las áreas, desconocíamos sus relaciones con el arte, y más concretamente con el arte contemporáneo.

Hasta ese momento, los contactos entre el CDAN y los usuarios de los hospitales se habían limitado a las actividades realizadas por los pacientes de hospitales psiquiátricos en nuestro espacio, así como las visitas guiadas a las exposiciones.

De cara a abordar mejor el proyecto "Arte contemporáneo en el hospital", comenzamos a reflexionar y estudiar las siguientes cuestiones: 
- El funcionamiento interno de los hospitales y del área sanitaria en Aragón.

- Posibles relaciones que puedan tener las personas ingresadas con el arte (talleres en los centros, salidas a museos...)

- Experiencias previas de otros centros que ya estén trabajando en este ámbito.

Los primeros pasos que dimos desde el CDAN en esta dirección, pasaron por personas que ya habíamos conocido en anteriores proyectos y que podrían servirnos de "puente" para acceder a instituciones hospitalarias que, a priori, eran desconocidas para nosotras. Javier Olivera, psiquiatra coordinador del área de Salud Mental de Huesca, nos aconsejó trabajar con el Centro de rehabilitación psicosocial Santo Cristo de los Milagros, de Huesca. Los pacientes de este centro habían acudido alguna vez al visitar las exposiciones del CDAN.

Es importante señalar que los contactos que hemos ido realizando a lo largo de nuestra andadura en el CDAN han sido fundamentales cuando hemos tenido que abordar nuevos campos desconocidos para nosotras. De ahí que la implicación personal de los profesionales (en este caso desde el museo o centro de arte y desde el hospital) sea fundamental para la ejecución de proyectos como este que, por su novedad, pueden causar rechazo en un primer momento, ya que de alguna forma suponen un sobreesfuerzo para ellos. Implica por lo tanto correr un riesgo ya que se trata de una actividad nueva, sin referencias previas, sin garantías de consecución, etc.

El Centro de rehabilitación en cuestión se sitúa en las afueras de Huesca, en un edificio de nueva construcción. En este nuevo edificio, se han atendido ciertos criterios de humanización de los espacios: solo tiene una altura, todas las habitaciones tienen amplios ventanales, está rodeado de zonas verdes y comunicado con la ciudad de Huesca a través de un sendero. En este centro se prestan los siguientes servicios:

- Unidad de media estancia: Es un centro de internamiento que presta una atención individualizada intensiva destinada a la rehabilitación del paciente. La estancia máxima de los pacientes es de 6 a 12 meses. Esta unidad está destinada a la atención de pacientes con trastornos mentales graves, que no responden al tratamiento ambulatorio y presentan una problemática psicosocial que requiere una hospitalización psiquiátrica que no puede realizarse en las unidades de hospitalización breve (centros de día o unidades de agudos), bien porque requiere amplios espacios o por la necesidad de un abordaje de rehabilitación intensivo. Los pacientes no acceden directamente a este recurso, ya que los ingresos se producen exclusivamente por indicación de una comisión técnica de ingresos.

- Unidad de larga estancia: Es el dispositivo resultante de transformar los antiguos manicomios en hospitales psiquiátricos. Está compuesto por dos tipos de usuarios. Por un lado, personas con enfermedad mental grave en régimen de larga estancia y que presentan grandes dificultades de adaptación a su entorno, con edades, en general, inferiores a los 65 años. Por otro lado, personas de más de 65, provenientes en su mayoría de los antiguos centros psiquiátricos, en los que el centro actúa como unidad residencial asistida cuando, por su estado, no se pueden derivar a sus casas o a residencias comunes. Dispone, además, de unidades de atención a colectivos específicos: gerontopsiquiatría, dementes con trastorno de conducta grave, psicosis refractarias, pacientes judiciales, etc. 
Comenzamos los primeros contactos con los profesionales del centro, el psiquiatra y la terapeuta ocupacional. Les propusimos la posibilidad de realizar un "taller de artista" en el que, de alguna forma, pudiéramos hacer llegar a los pacientes del centro un tipo de experiencia artística, que partiese directamente del motor de esta, es decir, del artista. Ambos profesionales se mostraron encantados de colaborar en el proyecto.

La disciplina trabajada o los contenidos conceptuales que tuviera el taller no constituyeron ningún impedimento, nos dieron total libertad para elegir temática y disciplina.

El objetivo de esta reunión era determinar los siguientes aspectos:

- Número de participantes: nos recomendaron que el grupo no superase las quince personas, acordamos acotar la participación a diez.

- Tipo de participación de los profesionales de la institución: consideramos necesario que estuviesen presentes durante la ejecución del taller las personas que conocían a los pacientes, sus características y cómo actuar en caso de alguno de ellos sufriera una crisis. La participación del personal sería activa, es decir, serían participantes del taller, pero estando atentos a los problemas que pudieran surgir.

- Características de los pacientes que debíamos conocer para el correcto diseño y desarrollo del taller. Se nos informó de las situaciones de todos los pacientes, pero sin determinar cual era exactamente el trastorno que padecía cada uno. Ya que esta información, podría condicionar nuestro comportamiento hacia ellos y mermar nuestra naturalidad en el trato.

Nos planteamos entonces la elección del artista, cuestión determinante, pues constituye la apuesta casi más importante por parte del centro de arte, y de su efectividad y resolución depende gran parte del éxito o fracaso de la acción.

La persona elegida por nosotras para diseñar el taller y llevarlo a cabo fue la fotógrafa Vicky Méndiz. Los criterios para elegirla fueron varios: su experiencia en el trabajo como educadora con grupos de diferentes ámbitos (escolares, público no especializado, público con necesidades especiales), su sensibilidad personal, su multidisciplinariedad, así como la calidad de su trabajo artístico. ${ }^{2}$

2. Vicky Méndiz es licenciada en Historia del Arte, ha estudiado el Master Gestión Cultural en la Universidad de Zaragoza y obtuvo en esta misma universidad, el Diploma de Estudios Avanzados con la tesina sobre la obra del fotógrafo Pedro Avellaned. Posteriormente realiza el Ciclo Formativo de Grado Superior en Fotografía Artística en la Escuela de Arte de Huesca. Desde el año 2001 ha participado en diversas exposiciones colectivas en espacios cómo el Museo Pablo Serrano de Zaragoza, el Museo de Huesca, Museo de Teruel, Palacio de Sástago o Cuarto Espacio de la Diputación de Zaragoza, PhotoEspaña 2008. También ha llevado a cabo proyectos individuales, cómo su intervención Vouyeur en el Proyecto Corner del Espacio para el Arte de Caja Madrid en 2006, o el proyecto Kokoro, fruto de su viaje a Japón en el 2007. cunado la fue artista becada para colaborar en el proyecto S-AIR del Inter Cross Creative Center de Sapporo, Japón y cuyos resultados pudieron verse en la Galería Spectrum Sotos de Zaragoza en 2008. Su obra forma parte de diversas colecciones pertenecientes al Gobierno de Aragón, Fundación Norte y Fundación Uncastillo. Ha sido profesora de fotografía en la Escuela de Fotografía Spectrum Sotos, y en instituciones cómo Diputación Provincial de Zaragoza y Obra Social Caja Madrid. Trabaja como fotógrafa freelance para estudios de arquitectura, catálogos de exposiciones, foto fija para productoras de cine como Cierzo Films . Actualmente elabora diversos proyectos de ámbito artístico en los que continua su línea de trabajo sobre el mono-no-aware para adentrarse en el misterio de lo cotidiano a través de la sinestesia, y el trabajo con la narrativa de la memoria con familiares de víctimas asesinadas durante la guerra civil española. 
Tras escoger a los compañeros de viaje, se imponía pautar la colaboración.

Se solicitó a la artista que nos planteara diversas posibilidades de talleres que pudiéramos realizar con este colectivo.

Las condiciones que a priori debía tener en cuenta para el diseño del taller fueron las siguientes:

La duración del taller: cada sesión no podía durar más de 90 minutos Esta restricción nos venía dada por la capacidad de atención que podían prestar los pacientes del Centro de rehabilitación.

Por las características del proyecto, y por las circunstancias de las personas que en él participaban, la realización del mismo debía llevarse a cabo en el propio centro hospitalario, tanto sus aulas como el espacio exterior.

Las personas participantes iban a ser adultos con capacidades cognitivas y físicas mermadas.

Con toda esta información, Vicky Méndiz llevó a cabo el diseño del taller, que fue totalmente aprobado por psiquiatra y terapeuta, ya que no hicieron ningún tipo de modificación ni adaptación. Las características del mismo quedaban entonces así:

Lugar: Centro de rehabilitación psicosocial Santo Cristo de los Milagros.

Participantes: diez personas de entre 40 y 80 años, con capacidades cognitivas medias-bajas, en internamiento en la unidad de larga estancia.

- Otros participantes: personal de la institución (psiquiatra y terapeuta educacional) y una educadora del CDAN.

- Duración del taller: cuatro sesiones de 90 minutos de duración, en cuatro lunes de los meses de marzo y abril de 2010.

- Objetivo del taller: acercar el lenguaje y la técnica de la fotografía a los usuarios y reflexionar sobre cómo nos vemos y sobre la idea que tenemos de cómo nos ven los demás.

En el taller se mostraba la fotografía, los dibujos y la palabra escrita como lenguaje artístico y herramienta que nos permite expresar sentimientos y emociones mediante la creación de imágenes y su posterior reflexión. Así se pretendía estimular la capacidad creativa, la expresión de emociones y sensaciones a través del medio fotográfico y el lenguaje; así como desarrollar la iniciativa individual y el trabajo en equipo.

A continuación pasamos a desarrollar el detalle de las sesiones que se llevaron a cabo:

Primera sesión: Para comenzar, educadora y artista debíamos presentarnos a los usuarios y explicarles, en qué iba a consistir el taller. También necesitábamos que se presentasen ellos, para conocernos mejor y comenzar a romper el hielo. Esto se hizo mediante un sencillo juego en el que, todos sentados en círculo, íbamos pasándonos un ovillo de lana. La persona que recibía el ovillo debía decir nombre y algo que le gustase hacer, y lo enviaba a otra persona. Finalmente quedaba una red de tela de araña realizada con la lana. 
Una vez presentados, mediante una presentación Powerpoint indagábamos en las características del lenguaje fotográfico a través de preguntas sencillas ¿Qué pensáis que es la fotografía? ¿Cómo es? ¿Qué tipos conocéis? ¿Hay una forma de mirar o hay muchas miradas? ¿De qué depende?, etc. Tratamos, constantemente, de que ellos mismos nos pusieran como ejemplo de sus opiniones alguna foto que tuviesen.

Finalmente, una vez introducido el concepto de fotografía artística, se repartieron diferentes objetos que nos servían para ir enmarcando la realidad que nos rodeaba (lupas, marcos de diapositivas, rollos de cartón...), para buscar, sobre un único espacio, diferentes miradas.

Segunda sesión: En esta sesión se planteaba ya la realización de fotografías por parte de los propios usuarios. Antes de realizarlas, la fotógrafa les explicaba el concepto de autorretrato y otras maneras de realizarlo que no fueran la representación del rostro, como por ejemplo la toma de fotografías de fragmentos y de elementos del entorno que les rodea. Toda esta explicación iba acompañada de imágenes de fotografías realizadas por Vicky Méndiz sobre este tema, de forma que ilustrara las ideas que se estaban trabajando.

El siguiente paso era realizar las fotos. Se les repartieron cámaras fotográficas desechables y un listado de partes del cuerpo que debían fotografiar, ${ }^{3}$ primero de su propio cuerpo y luego de un compañero o compañera a su elección, guiándoles, paso a paso, sobre las fotos que correspondían en cada momento. Esto último fue una recomendación que nos hicieron psiquiatra y terapeuta, ya que era muy probable que se despistaran y se dedicaran a fotografiar aleatoriamente lo que les interesase, obviando el tema del retrato.

Pese a la prevención, así sucedió y aunque algunos intentaron seguir la lista, en general, cada uno hizo lo que quiso y/o pudo. Se realizaron las fotografías en un espacio al aire libre.

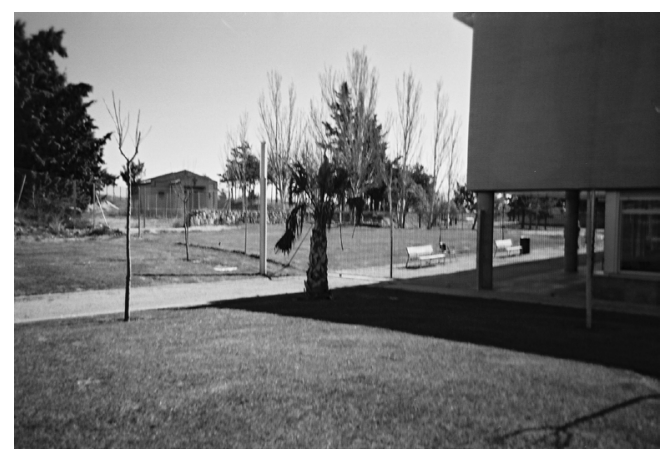

Fig.1.

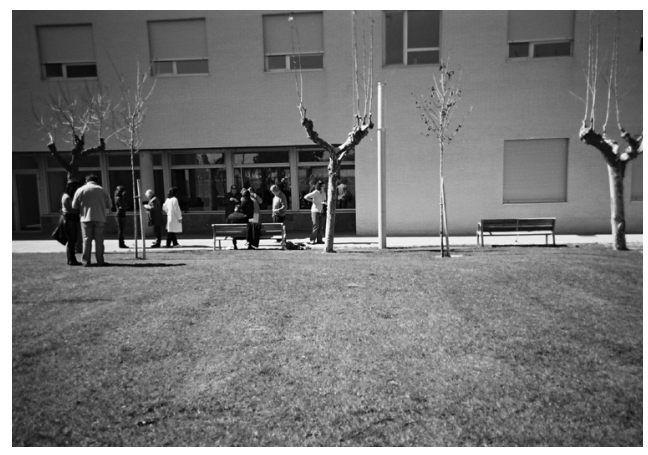

Fig.2

3. Una foto de mi mano o manos /De las manos de otra persona./Una foto de mi pie o zapato/Una foto de los pies o zapatos de otra u otras personas./Una foto de mis ojos./Una foto de los ojos de uno o varios compañeros. /Una foto de mi pelo./Una foto del pelo de uno o varios compañeros./Una foto de mi nariz/Una foto de la nariz de otra persona/Una foto de mis piernas/Una foto de las piernas de otros compañeros/Una foto de mi cabeza/Una foto de varias cabezas/Una foto de una cicatriz./Una foto de mi rostro/Una foto del rostro de varios compañeros/Una foto de cuerpo entero de otras personas/Una foto de perfil. /Una foto libre del entorno que nos rodea, de nuestros objetos, etc./Fotos libres. 
Fue un momento de trabajo libre dentro del grupo, en el que se vieron las relaciones entre los pacientes ("yo a estos no les fotografío por que son de pueblo" o "ponte que te hago una foto a tu gorra, a tus manos, a tus botas..." "has salido guapo"....etc.)

La ejecución de las fotografías supuso cierta dificultad técnica para los pacientes. Se utilizaron cámaras desechables y la mayoría de ellos no sabía o no tenía fuerza para girar la ruleta. En este punto entró nuestra labor como "asistentes de fotografia".

Algunos hicieron fotos sin parar hasta que se les acabo el carrete y otros fueron incapaces de hacer más de 7 fotos. Cada uno llevó su ritmo. Educadora, artista y terapeutas les ayudamos en todo momento e intentamos que todos realizaran la actividad, pero siempre respetando sus ritmos, sus necesidades y sus apetencias.

Estas son algunas de las imágenes que los pacientes realizaron: (fig.3,4.5 y 6 )

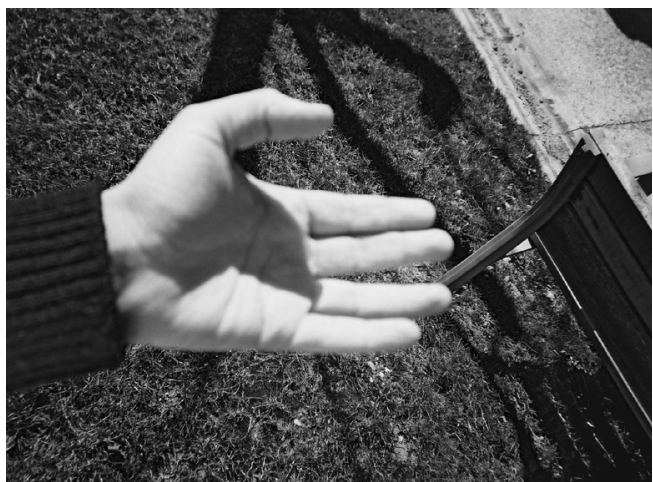

Fig.3.

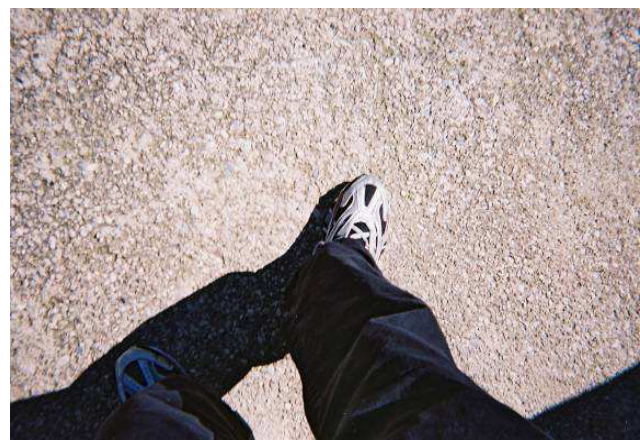

Fig.5

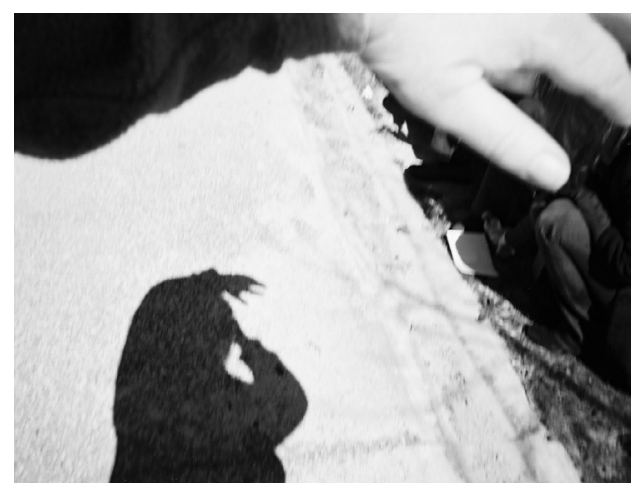

Fig.4.

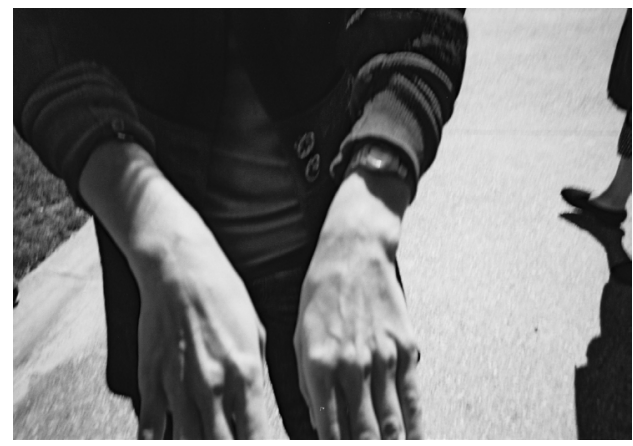

Fig.6

Mientras se iban realizando las fotografías, la artista tomó instantáneas de los pacientes. Después les pidió que le permitiesen realizarles un retrato "profesional". A esta petición todos respondieron de forma muy positiva excepto una de las participantes que no quiso ser retratada, ni de forma individual ni en grupo. En general esta persona se mostró en casi todas las sesiones muy reacia a participar, no le gustaba hacer fotos, ni que le hicieran. Su argumento fue no quería tener recuerdos (como nos comentaron posteriormente, esta paciente no conservaba ninguna foto anterior a su ingreso). 
Tercera sesión: Con las fotos ya reveladas, se les pidió que seleccionaran tres imágenes, las que más les gustasen, que apartaríamos para una actividad posterior.

Con las demás imágenes, formamos un álbum de fotografía personal. Para ello, primero cada uno creamos nuestro "cuaderno de artista" con folios y cartulinas de colores. Cada paciente fue pegando sus fotos en el cuaderno creado, eligiendo las que mas le gustaban o directamente desechando algunas. Aquí también pudimos observar aspectos acerca de la percepción que tenían sobre sí mismos y sobre el resto de los compañeros ("esta foto quiero romperla", en la que salía la propia persona retratada o "tú a mi no me pongas en tus fotos", porque no quería que otras personas tuvieran una imagen suya).

En dicho cuaderno, debían pegar las imágenes que habían tomado, buscando una palabra, frase o texto que quisieran asociar a cada una de ellas.

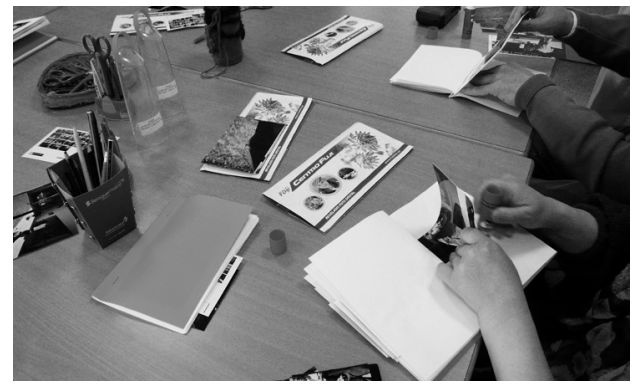

Fig.7

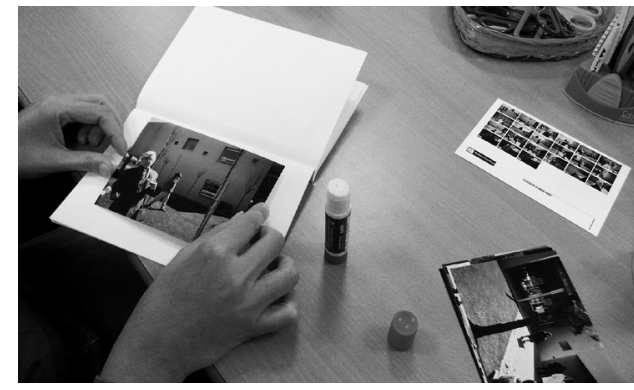

Fig. 8

Para realizar esta actividad y que pudieran comprender mejor qué era un cuaderno de artista, Vicky Méndiz trajo un cuaderno suyo, con muchas fotos, dibujos y anotaciones, que respondían a reflexiones personales relacionadas con su creación.

Para la mayoría de ellos fue muy difícil escribir algo acerca de las fotografías que no fuera exclusivamente descripción de la imagen. De hecho algunos ni siquiera acertaban a escribir ninguna palabra, porque "no se les ocurría nada". Fue esta una tarea en la que igualmente artista, educadoras, terapeuta y psiquiatra tuvimos que ayudarles mucho. Algunas personas se bloquearon y no escribieron nada. Otras nos preguntaban cuáles eran los nombres de las personas que aparecían en sus fotos.

En general los comentarios añadidos fueron puramente descriptivos, en algunos casos con cierto optimismo ("Vicky está guapísima en esta foto")

Cuarta sesión: Este fue el último día con ellos. Para concluir, era necesaria una visibilización de lo realizado, sobre todo en relación al resto de usuarios del centro, quienes no habían participado en el taller, pero nos habían visto con las cámaras trabajando.

Para ello, se rescataron las tres imágenes que cada usuario había apartado el día anterior, para colocarlas en unas cartulinas, a modo de panel. Estos paneles fueron expuestos en una pared del centro, en el hall del mismo, que normalmente se usa para colgar fotos de los viajes y excursiones que realizan juntos. Además de estas imágenes, añadimos una copia ampliada de los retratos realizados por la artista. 
Como actividad final, se invitó al resto de usuarios del Centro de rehabilitación a ver las obras realizadas por sus compañeros.

\section{Evaluación}

Los niños y adolescentes interpretan la hospitalización como un castigo por algo que han hecho mal, tienen miedo al abandono, presentan comportamientos regresivos, dependientes y pérdida de autoestima. La ansiedad y depresión son las principales alteraciones emocionales y la discontinuidad en la vida del niño y el adolescente enfermo, se caracteriza por: la interrupción de sus actividades y alteración de la normalidad; pérdida del control sobre el entorno y sobre sí mismo; transformación y adaptación; incertidumbre sobre el futuro; y cambios en la vida personal, social, familiar y escolar (Ullán y Belver, 2008).

Se realizó una cuádruple evaluación a los cuatro agentes participantes: los usuarios, a través de entrevistas con el psiquiatra; el personal socio-sanitario; la artista y nosotras, las educadoras del CDAN.

La evaluación por nuestra parte fue positiva, pero con matices. Por un lado, de los 10 usuarios que comenzaron el taller, lo finalizaron solo 8 personas. De estas dos personas, ninguna abandonó por voluntad propia el taller. Su ausencia se debió a circunstancias personales que les impedían estar físicamente en el centro durante el desarrollo de las últimas sesiones. Este dato nos demuestra que les resultó interesante. No obstante, tuvimos serias reticencias respecto al resultado, ya que habíamos percibido comentarios que denotaban cierto descontento.

Esta inquietud fue aclarada posteriormente por el psiquiatra en su evaluación. Respecto a nuestro papel, si bien en un principio nosotras valoramos realizar también el taller como un participante más, finalmente nuestra labor fue de "ayudantes" en la ejecución, ya que era la tarea que se nos solicitaba por parte de los participantes.

La artista, desde su vivencia personal, consideró que el taller había sido un éxito porque se alcanzaron los objetivos planteados en el proyecto inicial. Consideró que la acogida positiva del proyecto por parte del psiquiatra, la terapeuta y la enfermera del centro fue fundamental para el buen desarrollo del taller en las diferentes sesiones. Se sintió muy cómoda viendo cómo disfrutaban de la experiencia, sorprendida por la frescura y la magia de algunas de las imágenes que captaron y agradecida hacia ellos por la disponibilidad y el interés que mostraron (ver anexo I)

La evaluación del personal sociosanitario vino, finalmente, conjunta con la de los usuarios, ya que, por sus capacidades, no son capaces de rellenar una encuesta. La metodología empleada para obtener su valoración fue la entrevista directa por parte del psiquiatra. Este había realizado una evaluación sobre el estado de los pacientes antes de comenzar el taller, y otra después. Sobre las opiniones que vertieron sobre el taller, fueron en general positivas. Aunque no todos los usuarios acabaron contentos, a algunos les sirvió para tocar aspectos que les convendría trabajar (aunque no les resultara fácil ni satisfactorio), como la autoestima, la percepción propia, la imagen que tienen hacia los demás, etc.

El motivo del descontento no era tanto por la ejecución del taller, si no por el hecho de verse retratados. La mayoría de estas personas tienen problemas de autoper- 
cepción y autoestima. En cualquier caso, este enfado se valoró de forma positiva por parte del psiquiatra, ya que consideró que ese era un objetivo a lograr: que "tocara" aquellos aspectos que aparecen dentro de su terapia. Valoró que era más positivo que se enfadaran, porque ello significaba tomar conciencia de la realidad, a que no dijeran nada, y realizaran el taller sin ningún afecto (ver anexo II)

\section{Conclusiones}

Como conclusión, esta experiencia, que viene como culminación de un breve proceso de investigación, nos ha servido para abrirnos las puertas a una nueva vía de trabajo por parte de los centros de arte contemporáneo.

En el CDAN buscamos que el centro de arte se conciba como un espacio de integración en sí mismo, ya que las actividades que se ofrecen son para todos los públicos, y por lo tanto, a través de acciones como esta incidimos en dicho objetivo.

Además, los profesionales del Centro de rehabilitación Santo Cristo de los Milagros, han descubierto en el CDAN una nueva herramienta de trabajo, tanto lúdica, como educativa y rehabilitadora.

Por nuestra parte, hemos aprendido enormemente de la experiencia, sobre todo en lo que respecta al trato con personas que padecen trastornos mentales. Además, este proyecto nos ha permitido descubrir nuevos públicos potenciales y maneras de acercarnos a ellos.

Respecto a la continuidad de nuestro trabajo en el hospital esta es, de momento, nuestra única experiencia desarrollada en el propio hospital. Posteriormente hemos realizado más talleres de artista y acciones concretas con estos mismos usuarios pero ya fuera del Centro de rehabilitación. Han sido los profesionales del centro los que han preferido que estas acciones se desarrollaran fuera de la institución (siempre que sus capacidades motrices no se vieran afectadas), de forma que sirvan a los usuarios para salir durante unas horas de su espacio habitual de residencia y puedan así visitar otros lugares, como el centro de arte, que les ayuden a "despejarse"; así como a entrar en contacto con otros ámbitos de su entorno donde el trato que reciben sea lo más normalizado posible.

\section{Anexo I}

El taller realizado los lunes de marzo y abril en el Centro de Rehabilitación Mental, Santo Cristo de los Milagros en Huesca era mi primera experiencia con este tipo de colectivo.

Desde mi vivencia personal, el taller fue un éxito porque se alcanzaron los objetivos planteados en el proyecto inicial, estimular la capacidad creativa visual y del lenguaje, desarrollar la iniciativa individual y el trabajo en equipo.

Todo esto se trabajo mediante la estimulación a buscar imágenes, la creación de un grupo de fotografías de su propio cuerpo y del entorno a través de cámaras desechables, la construcción de un pequeño cuaderno de campo dónde recoger las imágenes y las palabras que sirvieron para ordenar la experiencia del taller y cómo punto 
final la proyección de los resultados y retratos que les había tomado a ellos.

En la última parte se trato de reforzar el buen trabajo que ellos habían realizado y la imagen positiva que los demás tienen de ellos.

El taller ha sido un primer acercamiento al uso y manejo de la cámara fotográfica como medio de expresión artística con el que nos relacionamos con el mundo, y sobretodo un medio que les ha permitido acercarse a su imagen a través de su cuerpo (tanto en autorretratos como la que los otros les devolvían), y a la de sus compañeros. Esta parte ha sido fundamental por las dificultades que algunos de ellos presentaban con el tema de la auto-imagen hacia el exterior con resistencias a realizar el taller que no impidieron que todos participaran en el mismo y compusieran sus cuadernos con las opiniones, frases, o palabras sobres las imágenes que habían realizado.

Algunos demostraron una gran libertad a la hora de enfrentarse a la actividad que se planteaba, otros se bloqueaban y volvían a retomarla. Al final, todos mostraron agradecimiento por el taller y algunos, expresaron apertura a aprender cosas nuevas y a repetirlo.

El apoyo de mis compañeras y la acogida positiva del proyecto por parte del psiquiatra, la terapeuta y la enfermera del centro fue fundamental para el buen desarrollo del taller en las diferentes sesiones.

Yo me sentí muy cómoda viendo cómo disfrutaban de la experiencia, cercana en el contacto con el grupo, sorprendida por la frescura y la magia de algunas de las imágenes que captaron y agradecida hacia ellos por la disponibilidad y el interés que mostraron.

Vicky Méndiz

\section{Anexo II}

- ¿Creéis que los pacientes han salido contentos/beneficiados del taller?

Sí, algunos más y otros menos. A algunos les ha servido para tocar aspectos que deberían trabajar, como la autoestima, la percepción propia, la imagen que tienen hacia los demas, etc.

Por eso algunos de ellos se han enfadado o no han quedado especialmente contentos de su paso por el taller, pero no es su satisfacción lo que buscamos, si no que "toquen" aquellos aspectos que deben trabajar.

- ¿Qué os ha parecido la metodología utilizada en el taller?

Correcta, bien. Lo más interesante es la parte práctica, cuándo ellos han participado creando o haciendo algo (en este caso las fotografías). Aunque hubiera sido mejor que las educadoras que vinisteis hubierais sido los cuatro días la misma, para no despistarles. 
- ¿Y los tiempos?

Adecuados, una hora esta bien. Los que se cansaban antes salían y luego volvían.

- ¿Pensáis que deberíamos haber sabido qué le pasaba a cada paciente antes de empezar la actividad?

No, pensamos que es mejor que no sepáis todo sobre ellos, de esa forma el comportamiento es más natural y hay menos prejuicios.

- ¿Qué otra utilidad podría tener un centro de arte como el CDAN aquí en el hospital?

La que tiene, un lugar donde poder ir a ver exposiciones. Nos gustaría que nuestros pacientes salieran mucho e hicieran diferentes actividades. De hecho hemos pedido una subvención- proyecto de calidad para realizar otra actividad con vosotros y también una excursión a la Panera.

- ¿De qué pensáis que depende el poder llevar a cabo un proyecto como este? ES decir, ¿cuál es la forma mejor de contactar con un centro hospitalario para llevar a cabo un proyecto como este?

Lo mejor es tratar con las personas, y tratar de encontrar gente interesada. Las instituciones en sí mismas no se mueven, son las personas que trabajan en ellas, su interés por hacer cosas nuevas es lo más importante.

- Pensamos que sería bueno visibilizar proyectos como este, ¿qué pensais vosotros?

También lo pensamos, creemos que seria bueno que el Hospital psiquiátrico estuviera en el centro de Huesca, para que todo el mundo nos viera. De cara a la repercusión en prensa, nos parece bien, siempre que no salgan los rostros de los pacientes.

\section{Referencias}

Actas Congreso Internacional sobre arte contemporáneo como herramienta de inclusión social (2008) MACUF, La Coruña

Coll, C., Marchesi, A. y Paplacios, J. (1999) Desarrollo psicológico y educación. Vol. 3: Trastornos del desarrollo y necesidades educativas especiales, Alianza Editorial S.A., Madrid

Marset, R. y Venosa, V.J.. (2001) Integración de personas con Disminución Psíquica en el Tiempo Libre, Editorial CCS, Madrid.

Ponce, A. (2005) ¿Qué le pasa a este niño? : una guía para conocer a los niños con discapacidad, Ediciones Serres S.L., Barcelona 
VVAA (2010). Arte contemporáneo y educación especial. Centre d'Art La Panera, CDAN,Es Baluard, Huesca

VVAA (2007) Culture et handicap. Guide practique de l'accesibilité. Ministere de la culture et de la communication, París.

VVAA (2010) Experiencias de aprendizaje con el arte actual en las políticas de la diversidad. Educación y Acción Cultural MUSAC, León 